http://jmscr.igmpublication.org/home/ ISSN (e)-2347-176x ISSN (p) 2455-0450

crossref DOI: https://dx.doi.org/10.18535/jmscr/v9i1.51

\title{
Comparison of three different phenylephrine infusion regimens in preventing maternal hypotension in parturients undergoing cesarean section under spinal anaesthesia
}

\author{
Authors
}

\author{
Dr Anmolpreet Kaur ${ }^{1}$, Dr Bhawna Soni ${ }^{2}$, Dr Ankita Chandel ${ }^{3}$, \\ Dr Manjit Singh Kanwar ${ }^{4}$, Dr Nisha Sharma ${ }^{5}$, Dr Gaurav Kuthiala ${ }^{6}$ \\ ${ }^{1}$ Senior Resident, Government Medical College, Chandigarh \\ ${ }^{2,5}$ Senior Resident, Dr Radhakrishnan Government Medical College, Hamirpur \\ ${ }^{3,4}$ Assistant Professor, Dr Radhakrishnan Government Medical College, Hamirpur \\ ${ }^{6}$ Consultant Anaesthesia, SPS Hospitals, Ludhiana \\ *Corresponding Author \\ Dr Manjit Singh Kanwar
}

\begin{abstract}
Background: There is accumulating evidence that Phenylephrine delivered as an infusion is the most effective method for preventing maternal hypotension and intra-operative nausea and vomiting. We designed a double-blind, placebo-controlled study to find out the optimal infusion dose that is associated with least number of physician interventions needed to maintain maternal systolic blood pressure (SBP) within $20 \%$ of baseline.

Methodology: With due permission of ethical committee and written informed consent of the patients, ASA physical status I and II pregnant women with singleton gestation at a gestational age of $>36$ weeks were recruited for the study. Parturients were randomly allocated to a placebo group (PEO) or three fixed rate phenylephrine infusion

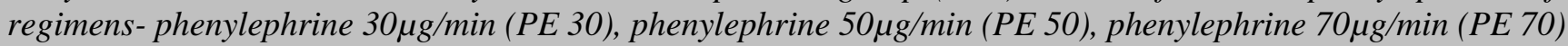

Results: The hypotension episodes were also significantly more frequent in group PEO compared to groups PE30, $P E 50$ and PE70. Maximum fall in SBP from baseline was significantly reduced in phenylephrine groups PE50 and PE70 compared PEO.

Conclusion: Phenylephrine administered as prophylactic infusion at fixed rate of 50 $\mu \mathrm{g} / \mathrm{min}$ initiated immediately after subarachnoid block in caesarean section maintains greater maternal hemodynamic stability.
\end{abstract}

\section{Introduction}

In caesarean section, an incidence of $70-80 \%$ of hypotension has been reported after spinal anaesthesia. ${ }^{1}$ If severe, it can result in adverse perinatal outcomes such as reduction in uteroplacental blood flow, disruption of fetal oxygenation, fetal acidosis and maternal symptoms such as nausea, vomiting and altered level of consciousness. ${ }^{2}$ There is accumulating evidence that Phenylephrine delivered as an infusion is the most effective method for preventing maternal hypotension and intraoperative nausea and vomiting. ${ }^{1,3,4}$ Still the best infusion rate of phenylephrine for control of spinal hypotension is not known as an overdose may cause hypertension, reflex bradycardia and decreased maternal and fetal cardiac output, whereas, lower doses may not be adequate to prevent hypotension. We designed a double-blind, placebo-controlled study to find out the optimal infusion dose that is associated with least number of physician interventions needed to maintain maternal systolic blood pressure (SBP) within $20 \%$ of baseline. Our primary objective was to determine the number of physician interventions needed to maintain maternal SBP within $20 \%$ of 
baseline or $>90 \mathrm{~mm} \mathrm{Hg}$ and to treat bradycardia, whereas, secondary objectives were to determine impact on intra-operative nausea and vomiting, neonatal Apgar score and fetal acidosis.

\section{Methodology}

On admission of pregnant women for elective caesarean section, a detailed pre-anaesthesia check up was conducted. After taking permission by ethical committee, ASA physical status I and II pregnant women with singleton gestation at a gestational age of >36 weeks scheduled for elective caesarean delivery under spinal anaesthesia were recruited. Written informed consent was taken from all the parturients. We excluded women who were in labor, had a body mass index $>40 \mathrm{~kg} / \mathrm{m} 2$, Type 1 diabetes mellitus, pre-existing or pregnancy induced hypertensive disease, cardiac or cerebrovascular disease, a fetus with severe congenital anomalies/intra-uterine growth retardation, history of monoamine oxidase inhibitor use, those who were included in any other anesthesia drug studies, or when there was any contra-indication to spinal anaesthesia. Parturients were admitted to the preoperative area on the morning of their caesarean delivery. They had a 20-gauge IV cannula inserted into a dorsal hand vein, preferably of non-dominant hand, which was then connected to a three-way stopcock flushed with normal saline. Injection (Inj.) Ranitidine 50mg and inj. Metoclopramide 10mg were given intravenously half an hour before surgery.

Parturients were randomly allocated to a placebo group (PE0) or three fixed rate phenylephrine infusion regimens- phenylephrine $30 \mu \mathrm{g} / \mathrm{min}$ (PE 30), phenylephrine $50 \mu \mathrm{g} / \mathrm{min}$ (PE 50), phenylephrine $70 \mu \mathrm{g} / \mathrm{min}$ (PE 70). For the purpose of double blinding, the study drug for the different groups was prepared in varying concentrations of Phenylephrine in identical looking $50 \mathrm{ml}$ syringes so that the final volume of each study drug and the rate of infusion remain the same. In operation theatre, routine monitors were attached and standard non-invasive monitoring was done including electrocardiogram (ECG), non-invasive blood pressure (NIBP), blood oxygen saturation $\left(\mathrm{SpO}_{2}\right)$. Baseline arterial blood pressure and heart rate were measured in supine position with left uterine displacement. Baseline SBP and heart rate were determined by calculating the mean of 3 consecutive readings taken 3 minutes apart. Baseline SBP was then used to determine acceptable range of $\pm 20 \%$ outside of which a physician intervention was indicated. We used a lower limit of $90 \mathrm{~mm} \mathrm{Hg}$ in women in whom a $20 \%$ reduction in baseline SBP was found to be $<90 \mathrm{~mm} \mathrm{Hg}$. Spinal anaesthesia was performed in sitting position at L3-L4 or L4-L5 interspace using 26-guage Quincke's spinal needle with $2 \mathrm{ml}$ $0.5 \%$ heavy Bupivacaine + Inj. Fentanyl 20 $\mu$ g (B Braun Medical, Inc., Bethlehem, PA). Immediately after intrathecal injection, fluid coload of balanced crystalloid @ $15 \mathrm{ml} / \mathrm{kg}$ was administered by gravity over a period of approximately 10-15 minutes, then the rate of administration of IV fluid was reduced to keep the vein open till delivery. At the same time, infusion of the study drug was started @ 30ml/hour via 3way stopcock connected directly to the IV cannula. Women were immediately laid supine with $5-10^{\circ}$ head down tilt with left uterine displacement. The cephalad extent of the sensory block was assessed every minute after giving spinal anaesthesia using loss of pin prick sensation till the loss of sensation upto T4 level and surgery was allowed to start then. Non-invasive blood pressure readings were taken every minute (min.) till the delivery and then every 2 minutes till 10 minutes after delivery. Heart rate, ECG were monitored continuously and readings were recorded every minute till the end of the study period. After delivery, inj. Methergin $0.2 \mathrm{mg}$ was given intravenously slowly over 2 minutes and $20 \mathrm{U}$ Syntocin (Oxytocin) was given by an infusion in 1 litre fluid over 1 hour. Study drug was infused until 10 minutes after delivery, after which the study ended.

Number of physician interventions needed to maintain maternal SBP within $20 \%$ of baseline 
and to treat bradycardia during the study period were recorded. Decrease in SBP $>20 \%$ of baseline or $<90 \mathrm{~mm} \mathrm{Hg}$ was treated by giving $50 \mu \mathrm{g}$ bolus of phenylephrine; an increase in SBP to $>20 \%$ of baseline was treated by stopping the infusion. Infusion was restarted only when SBP decreased to below the upper limit of the target range. Bradycardia (defined as $\mathrm{HR}<50 \mathrm{bpm}$ ) was treated by giving $0.6 \mathrm{mg}$ Atropine IV. If the study drug infusion had to be stopped for 3 occassions, then it was stopped permanently and blood pressure was maintained with phenylephrine boluses for the remaining study. We recorded the number of parturients who experienced any episode of hypotension, reactive hypertension, bradycardia in each group. We also recorded the number of hypotensive and hypertensive episodes per parturient in each group.

The occurrence of intra-operative nausea and vomiting was recorded and severity was rated using a four point scale ${ }^{5}$ : $(0=$ none, $1=$ mild nausea, 2 = nausea requiring treatment, $3=$ vomiting). The parturients were asked to report nausea at any time during the study time. Nausea or vomiting with a score of 2 or 3 was treated with inj. Ondansetron $4 \mathrm{mg}$ IV if unrelated to hypotension. Nausea and vomiting associated with hypotension was recorded as hypotension induced nausea and vomiting. Apgar score was recorded by paediatrician at 1 and 5 minutes after delivery. Blood samples collected from a double-clamped segment of the umbilical cord were immediately read for umbilical artery blood gases using GEM $^{\circledR}$ Premier 4000 Blood Gas Analyzer. The highest level of sensory block, time from skin incision to delivery, uterine incision to delivery, volume of crystalloid solution infused during the study period were also recorded.

\section{Statistical Analysis}

In a study by Allen et $\mathrm{al}^{6}$ in 2010 , for $\alpha=0.05$ and $1-\beta=0.95,20$ parturients per group were required. Therefore, we worked on the idea given from the above mentioned study that securing a maximum number of initial cases would be conductive in obtaining a high statistical power. We enrolled 80 parturients in the study. The power of our study was found to be more than $95 \%$.

All the relevant data was collected. Statistical analysis of data was done by SPSS (version 17) statistics package software. Data was tested for normality using Kolmogorov-Smirnov test. Unpaired student's t test and Mann-Whitney U test and ANOVA test and Chi-square test were used for categorical data. Data was expressed as mean \pm standard deviation (SD), percentage or median (range). The data with $\mathrm{p}$ value less than 0.05 was considered statistically significant.

\section{Results}

Eighty parturients were recruited for this study. There were no significant differences among the groups in parturient demographic characteristics, maximum height of the sensory block, volume of balanced crystalloid solution infused, skin incision to delivery time and uterine incision to delivery time (Table 1). Hemodynamic data is presented in Table 2.

The incidence of pre-delivery hypotension was significantly reduced in groups PE30 (45\%), PE50 (20\%), PE70 (10\%) compared with group PE0 $(80 \%)$. The incidence was also significantly lower in group PE70 compared to group PE30. In group PE0, out of 20 parturients, 7 parturients (35\%) experienced post-delivery hypotension which was significantly high compared to groups PE30, PE50 and PE70 in whom none of the parturients $(0 \%)$ experienced post-delivery hypotension. The hypotension episodes were also significantly more frequent in group PE0 compared to groups PE30, PE50 and PE70. Pre-delivery hypertension was seen in 12 parturients $(60 \%)$ in group PE70 which was significantly high compared to placebo. It was also significantly high compared to PE30 and PE50 where incidence was only 5\% and $10 \%$ respectively. The incidence of post-delivery hypertension in PE70 (25\%) was also significantly high compared to control (0\%). Similarly, hypertensive episodes were significantly more frequent in PE70 compared to lower infusion groups PE0, PE30 and PE50. But phenylephrine 


\section{JMSCR VoI||09||Issue||01||Page 279-286||January}

infusion was not required to be stopped permanently in any of the groups. Maximum fall in SBP from baseline was significantly reduced in phenylephrine groups PE50 and PE70 compared PE0. It was also significantly reduced in PE70 compared to PE30. Maximum rise in SBP from baseline was significantly high in groups PE30, PE50 and PE70 compared to PE0.The maximum rise in SBP was significantly high in group PE70 compared to groups PE30 and PE50 also.The mean maximum rise and fall in SBP remain within $20 \%$ of baseline in PE50 as compared to PE30 and PE70.

There were no significant differences in the incidence of bradycardia among the groups. The number of interventions were significantly less in groups PE30, PE50 and PE70 compared to PE0.
The incidence of intra-operative nausea and highest nausea score was significantly less in groups PE50 and PE70 compared to group PE0. All nausea episodes were hypotension induced. There were no differences in incidence of vomiting among the groups (Table 3 ).

There were no significant differences in 1 and 5 minute Apgar scores and umbilical cord gases in all the groups (Table 4). There were also no differences in the incidence of fetal acidosis among the groups. Three out of four subjects who were given atropine bolus in response to bradycardia experienced adverse effect of reactionary severe hypertension after administering atropine.

Table 1. Demographic data

\begin{tabular}{|lccccc|}
\hline & PE0 $(\mathrm{n}=20)$ & PE30 $(\mathrm{n}=20)$ & PE50 $(\mathrm{n}=20)$ & PE70 $(\mathrm{n}=20)$ & $\mathrm{p}$ value \\
\hline Age $(\mathbf{y r})$ & $29.95 \pm 4.35$ & $29.55 \pm 3.24$ & $29.45 \pm 2.70$ & $30.50 \pm 4.76$ & 0.821 \\
\hline Height $(\mathbf{c m})$ & $160.39 \pm 2.35$ & $159.28 \pm 4.36$ & $159.29 \pm 4.02$ & $158.87 \pm 1.92$ & 0.520 \\
\hline Weight $(\mathbf{k g})$ & $69.20 \pm 6.99$ & $69.65 \pm 8.13$ & $70.44 \pm 9.65$ & $68.83 \pm 5.96$ & 0.924 \\
\hline Highest level of sensory block & & & & & \\
\hline $\begin{array}{l}\text { Volume of crystalloid solution } \\
\text { (m) }\end{array}$ & $\begin{array}{c}1125.00 \pm 93 . \\
89\end{array}$ & $1162.50 \pm 119.07$ & $1140.00 \pm 119.87$ & $1105.00 \pm 93.05$ & 0.387 \\
\hline $\begin{array}{l}\text { Skin incision to delivery time } \\
\text { (min) }\end{array}$ & $7.80 \pm 1.47$ & $8.30 \pm 1.13$ & $8.10 \pm 0.97$ & $7.65 \pm 1.18$ \\
\hline $\begin{array}{l}\text { Uterine incision to delivery } \\
\text { time(min) }\end{array}$ & $1.70 \pm 0.47$ & $1.75 \pm 0.44$ & $1.75 \pm 0.44$ & $1.80 \pm 0.41$ & 0.321 \\
\hline
\end{tabular}

Table 2. Hemodynamic Variables

\begin{tabular}{|lcccc|} 
& PE0 $(\mathbf{n = 2 0})$ & PE30 $(\mathbf{n = 2 0})$ & PE50 $(\mathbf{n = 2 0})$ & PE70 $(\mathbf{n = 2 0})$ \\
\hline Pre-delivery hypotension & $16(80 \%)^{*}$ & $9(45 \%)$ & $4(20 \%)$ & $2(10 \%) \dagger$ \\
\hline Post-delivery hypotension & $7(35 \%)+$ & $0(0 \%)$ & $0(0 \%)$ & $0(0 \%)$ \\
\hline Pre-delivery hypertension & $0(0 \%)$ & $1(5 \%)$ & $2(10 \%)$ & $12(60 \%) \S$ \\
\hline Post-delivery hypertension & $0(0 \%)$ & $1(5 \%)$ & $1(5 \%)$ & $5(25 \%) \|$ \\
\hline No. of hypotensive episodes & $4.00 \pm 3.15 \Phi$ & $1.00 \pm 1.30$ & $0.20 \pm 0.41$ & $0.10 \pm 0.31$ \\
\hline No. of hypertensive episodes & $0.00 \pm 0.00$ & $0.50 \pm 2.24$ & $0.35 \pm 1.18$ & $1.65 \pm 2.01 * *$ \\
\hline Maximum percentage fall in SBP & $27.10 \pm 7.69 \dagger \dagger$ & $21.37 \pm 15.56$ & $16.64 \pm 7.35$ & $13.67 \pm 8.35+\dagger$ \\
\hline Maximum percentage rise in SBP & $1.42 \pm 3.42 \ddagger$ & $11.38 \pm 12.53$ & $12.30 \pm 7.41$ & $22.45 \pm 12.61 \psi$ \\
\hline No. of interventions & $4.00 \pm 3.15 \Phi$ & $1.15 \pm 1.35$ & $0.50 \pm 0.83$ & $1.35 \pm 1.35$ \\
\hline Infusion Permanently stopped & $0(0 \%)$ & $0(0 \%)$ & $0(0 \%)$ & $0(0 \%)$ \\
\hline Bradycardia & $0(0 \%)$ & $1(5 \%)$ & $1(5 \%)$ & $2(10 \%)$ \\
\hline
\end{tabular}

$\mathrm{PE}=$ phenylephrine; $\mathrm{SBP}=$ systolic blood pressure

Data are mean \pm SD or number $(\%)$

$* \mathrm{p}$ value PE0 vs PE30 $=0.024$, PE0 vs PE50 $=0.000$, PE0 vs PE70 $=0.000$

$\uparrow p$ value $\mathrm{PE} 30$ vs PE70 $=0.015$

$\$ p$ value PE0 vs PE30 $=0.004$, PE0 vs PE50 $=0.004$, PE0 vs PE70 $=0.004$

$\S \mathrm{p}$ value $\mathrm{PE0}$ vs $\mathrm{PE70}=0.000, \mathrm{PE} 30$ vs $\mathrm{PE70}=0.000, \mathrm{PE} 50$ vs $\mathrm{PE70}=0.001$ 


\section{JMSCR Vol||09||Issue||01||Page 279-286||January}

$\| \mathrm{p}$ value $\mathrm{PE} 0$ vs $\mathrm{PE70}=0.024$

II $p$ value $P E 30$ vs $P E 0=0.000$, PE30 vs $P E 0=0.000$, PE30 vs $P E 0=0.000$

$* *$ p value $\mathrm{PE70}$ vs $\mathrm{PE} 0=0.002$, PE30 vs PE70 $=0.027$, PE50 vs PE70 $=0.013$

†† $\mathrm{p}$ value $\mathrm{PE} 0$ vs $\mathrm{PE} 50=0.002$, $\mathrm{PE} 0$ vs PE70 $=0.000$

$\$$ t $p$ value $P E 70$ vs $P E 30=0.021$

$\ddagger p$ value $P E 0$ vs $P E 30=0.002$, PE0 vs PE50 $=0.001$, PE0 vs PE70 $=0.000$

$\Psi$ p value $P E 70$ vs $P E 30=0.001$, PE70 vs PE50 0.002

II pvaluePE0 vs PE30 $=0.000$, PE0 vs PE50 $=0.000$, PE0 vs PE70 $=0.000$

Table 3. Incidence of Intraoperative Nausea and Vomiting

\begin{tabular}{|lcccc|} 
& PE0 $(\mathbf{n = 2 0})$ & PE30 $(\mathbf{n}=\mathbf{2 0})$ & PE50 $(\mathbf{n = 2 0})$ & PE70 $(\mathbf{n = 2 0})$ \\
\hline Intra-operative nausea & $7(35 \%)^{*}$ & $3(15 \%)$ & $0(0 \%)$ & $0(0 \%)$ \\
\hline Hypotension induced nausea & $7(35 \%) \dagger$ & $3(15 \%)$ & $0(0 \%)$ & $0(0 \%)$ \\
\hline Intra-operative vomiting & $0(0 \%)$ & $0(0 \%)$ & $0(0 \%)$ & $0(0 \%)$ \\
\hline Highest nausea score & $0(0-1.0) \dagger$ & $0(0-0)$ & $0(0-0)$ & $0(0-0)$ \\
\hline
\end{tabular}

$\mathrm{PE}=$ phenylephrine.

Data are number (\%) or median (interquartile range).

$*$ p value PE0 vs PE50 $=0.004$, PE0 vs PE70 $=0.004$

$\uparrow \mathrm{p}$ value $\mathrm{PE0}$ vs $\mathrm{PE} 50=0.004, \mathrm{PE0}$ vs $\mathrm{PE70}=0.004$

$\$ \mathrm{p}$ value $\mathrm{PE0v}$ sE30 $=0.042, \mathrm{PE0vs} \mathrm{PE50}=0.001, \mathrm{PE} 0 \mathrm{vs} \mathrm{PE70}=0.001$

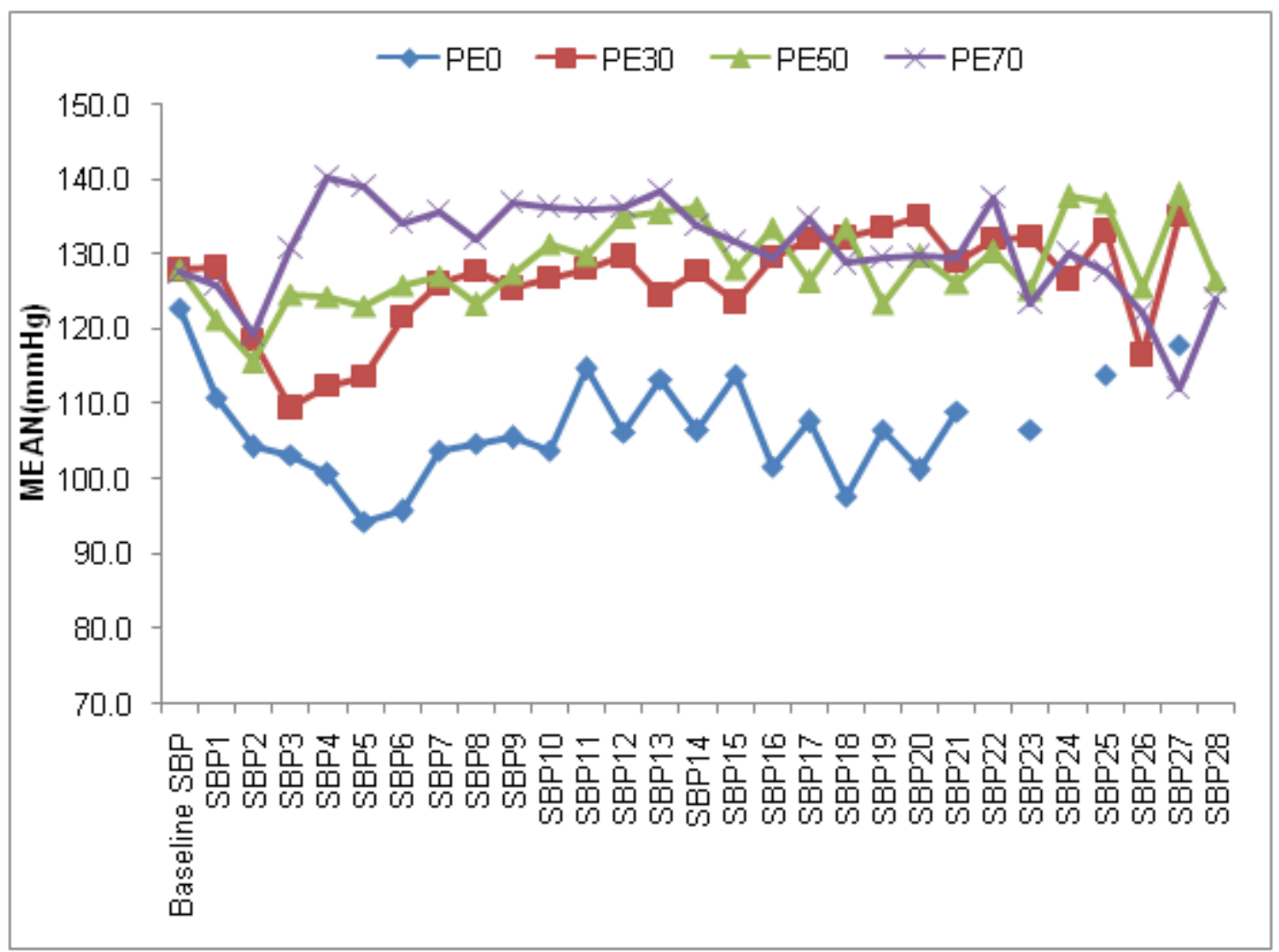

Figure 1. Systolic Blood Pressure trends in all groups

Table 4. Apgar score

\begin{tabular}{|lccccc|}
\hline & PE0 $(\mathrm{n}=20)$ & PE30 $(\mathrm{n}=20)$ & PE50 $(\mathrm{n}=20)$ & PE70 $(\mathrm{n}=20)$ & $\mathrm{p}$ value \\
\hline Apgar score at 1 min & $8(8-8)$ & $8(8-8)$ & $8(8-8)$ & $8(8-8)$ & 0.724 \\
\hline Apgar score at 5 min & $9(9-9)$ & $9(9-9)$ & $9(9-9)$ & $9(9-9)$ & 1.000 \\
\hline
\end{tabular}

$\mathrm{PE}=$ phenylephrine

Data is median (interquartile range) 
Table 5. Umbilical Cord Gas Data

\begin{tabular}{|c|c|c|c|c|c|}
\hline & PE0 $(n=20)$ & $\operatorname{PE} 30(n=20)$ & $\operatorname{PE} 50(n=20)$ & $\operatorname{PE70}(n=20)$ & $\mathrm{p}$ value \\
\hline $\mathbf{U A ~ P h}$ & $7.30 \pm 0.03$ & $7.31 \pm 0.03$ & $7.32 \pm 0.03$ & $7.32 \pm 0.06$ & 0.265 \\
\hline $\mathrm{UA} \mathrm{pO}_{2}(\mathrm{mmHg})$ & $20.10 \pm 1.86$ & $22.66 \pm 4.86$ & $20.91 \pm 4.90$ & $22.28 \pm 4.88$ & 0.217 \\
\hline $\mathrm{UA} \mathrm{pCO}_{2}(\mathrm{mmHg})$ & $46.76 \pm 3.98$ & $46.36 \pm 5.56$ & $45.62 \pm 4.30$ & $44.40 \pm 6.41$ & 0.494 \\
\hline UA Base Excess (mmol/l) & $-3.71 \pm 0.59$ & $-3.07 \pm 1.48$ & $-3.62 \pm 0.74$ & $-3.09 \pm 1.23$ & 0.121 \\
\hline
\end{tabular}

$\mathrm{PE}=$ phenylephrine; $\mathrm{UA}=$ umbilical artery

Data is mean $\pm \mathrm{SD}$

\section{Discussion}

It is now widely accepted that vasopressor of choice in the parturient is phenylephrine but the dosing and mode of administration of this drug still remain an area warranting further research. ${ }^{6,7,8,9,10,11,12,13}$ In this study, we found greater hemodynamic stability with the dose of $50 \mu \mathrm{g} / \mathrm{min}$ phenylephrine administered as fixed rate infusion compared with the doses 30 and $70 \mu \mathrm{g} / \mathrm{min}$. Phenylephrine at a dose of $50 \mu \mathrm{g} / \mathrm{min}$ was associated with a significant reduction in the incidence of predelivery hypotension and the number of hypotensive episodes compared with the control group. Dose of $70 \mu \mathrm{g} / \mathrm{min}$ was associated significantly high incidence of predelivery hypertension and frequency of hypertensive episodes compared to all lower dose groups. The reduction in SBP from baseline was found $t$ to be inversely proportional to the dose of phenylephrine infusion. It was significantly reduced with infusion doses 50 and $70 \mu \mathrm{g} / \mathrm{min}$ compared to placebo. Maximum rise in SBP was significantly high in PE70 compared to PE30 and PE50 also. Phenylephrine dose 50 $\mathrm{g} / \mathrm{min}$ maintained SBP at near baseline values and was seen to require minimum number of interventions compared to placebo.

Reactive hypertension is a concern with prophylactic phenylephrine infusion which is directly dose related. The administration of glycopyrrolate for the management of bradycardia may have also contributed to this. In retrospect, managing bradycardia by stopping the phenylephrine infusion may have reduced its administration and limited the incidence and magnitude of hypertension.
We continued the infusions postdelivery to attenuate the potential hemodynamic changes associated with the administration of IV oxytocin $^{14,15}$. Incidence of post-delivery hypotension was significantly reduced to $0 \%$ in all phenylephrine groups compared to $35 \%$ in placebo.

Hypotension has been identified as an important etiological factor for intra-operative nausea and vomiting $^{16}$ Several studies have identified a reduction in the incidence of nausea and vomiting when using phenylephrine for cesarean delivery under spinal anesthesia. ${ }^{4,7,17,18,19}$ The mechanism of this may be related to the attenuation of the increase in vagal tone accompanying the rapid decrease in preload associated with spinal anesthesia. ${ }^{7,20}$ Incidence of hypotension-induced nausea and severity of nausea was significantly reduced in the 50 and $70 \mu \mathrm{g} / \mathrm{min}$ groups compared to placebo.

There were no differences in apgar score and umbilical cord blood gas values among the groups despite a significantly higher incidence of maternal predelivery hypotension in the control group, probably because of the brief nature of those hypotensive episodes and their rapid treatment. This is in agreement with the results of a previous study showing no difference in fetal outcomes between patients receiving phenylephrine as a bolus or infusion. ${ }^{4}$

Our study has few limitations. First, we investigated the use of fixed rate phenylephrine infusion in conjuction with crystalloid coload of $15 \mathrm{ml} / \mathrm{kg}$. Our findings may not be applicable in situations when IV fluids are not coadministered or an alternative volume is administered. Second, the fixed rate infusion in our study lacked 
titration. When maternal systolic blood pressure got above the target range, the infusion was stopped and it was again restarted when SBP came within range. Many times, it was seen that When maternal systolic blood pressure got above the target range, the infusion was stopped and it was again restarted when SBP came within range. Many times, it was seen that SBP repeatedly shot above the target range after re-starting the infusion. So, titration or variable rate infusion seemed a better alternative to maintain hemodynamic stability.

For the purposes of this study, we collected hemodynamic data at 1-minute intervals for the first 10 minutes only and then every 2.5 minutes until the end of the study period, and may have missed opportunities in this later time period to intervene to maintain maternal SBP within the target range. Furthermore, the best infusion rate for a fixed rate regimen of $50 \mu \mathrm{g} / \mathrm{min}$ can be decreased to $30 \mu \mathrm{g} / \mathrm{min}$ after delivery as this lower dose significantly prevented post-delivery hypotension and there is no added benefit of giving higher dose. Virtually all studies on phenylephrine have been carried out on healthy subjects undergoing low risk elective caesarean deliveries. Because of the negative effects of phenylephrine on cardiac output and propensity to decrease uteroplacental flow, its safety is questionable in high risk cases such as compromised uteroplacental flow or increased resistance to flow, preeclampsia, labouring women and fetal pre-maturity.

Future studies are needed to investigate variable rate infusion regimens for the prevention of hypotension in this population and its safety in high risk population.

\section{Conclusion}

Prophylactic phenylephrine infusion is a safe and effective method of maintaining arterial blood pressure during spinal anaesthesia for caesarean delivery. Phenylephrine administered as prophylactic infusion at fixed rate of $50 \mu \mathrm{g} / \mathrm{min}$ initiated immediately after subarachnoid block in caesarean section maintains greater maternal hemodynamic stability, decreases nausea and has good neonatal outcome, therefore, we conclude that it is the most optimal dose for preventing maternal hypotension with minimal interventions in caesarean section under spinal anaesthesia.

\section{References}

1. Habib AS. A review of the impact of phenylephrine administration on maternal hemodynamics and maternal and neonatal outcomes in women undergoing cesarean delivery under spinal anesthesia. Anesth Analg. 2012;114(2):377-90.

2. Rout CC, Rocke DA. Prevention of hypotension following spinal anesthesia for cesarean section. Int Anesthesiol Clin. 1994;32:117-35.

3. NganKee WD. Phenylephrine infusions for maintaining blood pressure during spinal anesthesia for cesarean delivery: finding the shoe that fits. Anesth Analg. 2014; 118:496-8.

4. NganKee WD, Khaw KS, Ng FF, Lee BB. Prophylactic phenylephrine infusion for preventing hypotension during spinal anesthesia for cesarean delivery. Anesth Analg. 2004;98: 815-21.

5. Sen I, Hirachan R, Bhardwaj N, Jain K, Suri V, Kumar P. Colloid cohydration and variable rate phenylephrine infusion effectively prevents postspinal hypotension in elective Cesarean deliveries. J Anaesthesiol Clin Pharmacol. 2013;29(3):348-55.

6. Allen TK, George RB, White WD, Muir HA, Habib AS. A double-blind, placebocontrolled trial of four fixed rate infusion regimens of phenylephrine for hemodynamic support during spinal anesthesia for cesarean delivery. Anesth Analg. 2010;111(5):1221-29.

7. Cooper DW, Carpenter M, Mowbray P, Desira WR, Ryall DM, Kokri MS. Fetal and maternal effects of phenylephrine and 
ephedrine during spinal anesthesia for cesarean delivery. Anesthesiology. 2002;97:1582-90.

8. Lee A, NganKee WD, Gin T. A quantitative, systematic review of randomized controlled trials of ephedrine versus phenylephrine for the management of hypotension during spinal anesthesia for cesarean delivery. Anesth Analg. 2002;94:920-6.

9. Stewart A, Fernando $\mathrm{R}$, McDonald $\mathrm{S}$, Hignett R, Jones T, Columb M. The dosedependent effects of phenylephrine for elective cesarean delivery under spinal anesthesia. Anesth Analg. 2010;111(5): 1230-37.

10. Rizk SN, Girgis K, Sayed A M, Abdella RMN. The effect of different phenylephrine infusion rates on uteroplacental blood flow during cesarean delivery under spinal anesthesia. The Egyptian J Cardiothoracic Anesth. 2013;7:85-91.

11. Srinivasan NM, Gopalswamy NM. Optimal dose of phenylephrine infusion for management of maternal hypotension under spinal anaesthesia for caesarean delivery .Sri Lankan J Anaesthesiol. 2016; 24(2):64-9.

12. Lee A, NganKee WD, Gin T. A doseresponse meta-analysis of prophylactic intravenous ephedrine for the prevention of hypotension during spinal anesthesia for elective cesarean delivery. AnesthAnalg. 2004;98:483-90.

13. Smiley RM. Burden of proof. Anesthesiology 2009;111:470-2.

14. Langesaeter E, Rosseland LA, Stubhaug A. Hemodynamic effects of oxytocin during cesarean delivery. Int J Gynecol Obstet 2006;95:46-7
15. Thomas JS, Koh SH, Cooper GM. Haemodynamic effects of oxytocin given as i.v. bolus or infusion on women undergoing Caesarean section. $\mathrm{Br} \quad \mathrm{J}$ Anaesth 2007;98:116-9

16. Balki M, Carvalho JC. Intraoperative nausea and vomiting during cesarean section under regional anesthesia. Int $\mathbf{J}$ Obstet Anesth. 2005; 14:230-41.

17. Ngan Kee WD, Khaw KS, Ng FF. Comparison of phenylephrine infusion regimens for maintaining maternal blood pressure during spinal anaesthesia for Caesarean section. Br J Anaesth 2004; 92:469-74

18. Ngan Kee WD, Lee A, Khaw KS, Ng FF, Karmakar MK, Gin T. A randomized double-blinded comparison of phenylephrine and ephedrine infusion combinations to maintain blood pressure during spinal anesthesia for cesarean delivery: the effects on fetal acid-base status and hemodynamic control. Anesth Analg 2008;107:1295-302. 